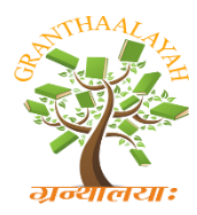

\author{
INTERNATIONAL JOURNAL OF RESEARCH - \\ GRANTHAALAYAH \\ A knowledge Repository
}

Science

\title{
DEVELOPMENT OF INSTRUCTIONAL COMPUTER MODEL FOR DESIGNING E-LEARNING MODULES FOR HEARING IMPAIRED PERSONS (TECHNICAL APPROACH)
}

\author{
Dr. Karim Q Hussein "1, Mrs. Qabas Abdal Zahraa Jabbar *2 \\ ${ }^{* 1}$ Assistance Prof./Computer Science Dept./Faculty of Science /Mustansiriyha \\ University/Baghdad - Iraq \\ ${ }^{* 2}$ Computer Science Dept./Faculty of Science /Mustansiriyha University/Baghdad - Iraq
}

\begin{abstract}
To develop an e-learning module for a certain topic, many factors must be taken into account. Each factor deals with a specific area of study, therefore such development does not represent a task of software skills, programming, or developing of multimedia. But it is an integrated work in which software development represents the main tool and the main factor of that work.

For Hearing Impaired Persons (HI) this work would be more difficult because the designer must consider specific factors represent the environment of teaching / learning process for HI person via e-Learning. According to our survey we did not find such systematic integrated model which would be a typical guide for developing e-learning modules (eLMs) for HI persons so that the developed eLMs would be systematic and realizing effective instructional outcomes.

The integrated and systematic approach, which has been used during the development of this model, results in a model that processes all requirements of designers who would like to develop their own eLMs for any topic and for any category of HI persons.
\end{abstract}

Keywords: HI: Hearing Impaired; eLMs: e-learning Modules; Instructional Computer Model.

Cite This Article: Dr. Karim Q Hussein, and Mrs. Qabas Abdal Zahraa Jabbar. (2019). "DEVELOPMENT OF INSTRUCTIONAL COMPUTER MODEL FOR DESIGNING ELEARNING MODULES FOR HEARING IMPAIRED PERSONS (TECHNICAL APPROACH)." International Journal of Research - Granthaalayah, 7(7), 207-217. https://doi.org/10.29121/granthaalayah.v7.i7.2019.755.

\section{Introduction}

The model represents a mental picture or computational framework based on a specific theory to stimulate behavior. It serves as an ideal guide to accomplish the desired production.

Therefore, the model represents a guide to develop the systematic and meaningful eLMs for HI students. 
Our model represents an interaction and integrate among many systems, the output of each system leads to the input of next system, Each system has its own elements as well as mechanism, this would explained in the next section.

\section{Objective of Research}

\section{All This research aims at:}

Developing a systematic model to be used by the designers who would like to develop their desired eLMs for any topic for HI persons. However, these eLMs would be developed so as to be systematic and realizing effective instructional outcomes to the HI student who would learn via these eLMs.

The designer who would like to develop an eLM for a topic must prepare the requirements of such development and analysis of the instructional material so as to be capable with the mechanism of the model.

\section{Q) Why eLMs for teaching HI students?}

eLMs enhanced by effective multimedia is a modern technology. Such technology can overcome the disability in learning audio mode material by translating it into corresponding material in visual modes like speech visualization of sign language, lip movement and finger spelling. Also modern technology of development eLMs provides many effective advantages to HI student while he/she uses eLMs as follow:

There are many advantages of e-learning for HI students

1) It provides individualization in teaching / learning process. It solves the problem of individual differences between HI students. HI student learns at his / her own speed and he / she can repeat the lesson many times. It thus accommodates diversity through universal design.

2) e-Learning allows HI student to take the main and active role in teaching / learning process via computer. When HI student takes such effective role, it is expected that HI student will carry on learning with motivation and self confidence, besides e-learning module includes reinforcement, immediate feedback, fun and enjoyment (learning through games).

3) HI students need effective visual mode of communication. The multimedia techniques using speech visualization can strongly provide the required visual effects (animation, images, pictures, diagrams, signs, charts, flashing, lighting, colors, etc.) to HI student. This visual output tries to overcome the hearing disability of HI students in the communication mode.

4) eLMs do not embarrass students who make mistakes.

5) eLMs offer sense of control over learning process.

6) eLMs Help student to evaluate himself.

\section{Presentation of The Model}

The Five stages of this model would be presented. Each stage is represented as a separate system so that system has its own elements as well as its own mechanism. 
As a whole aspect of mechanism, it is clear that the output of each system acts as the input of next system.

The next diagram shows the stages of the model.

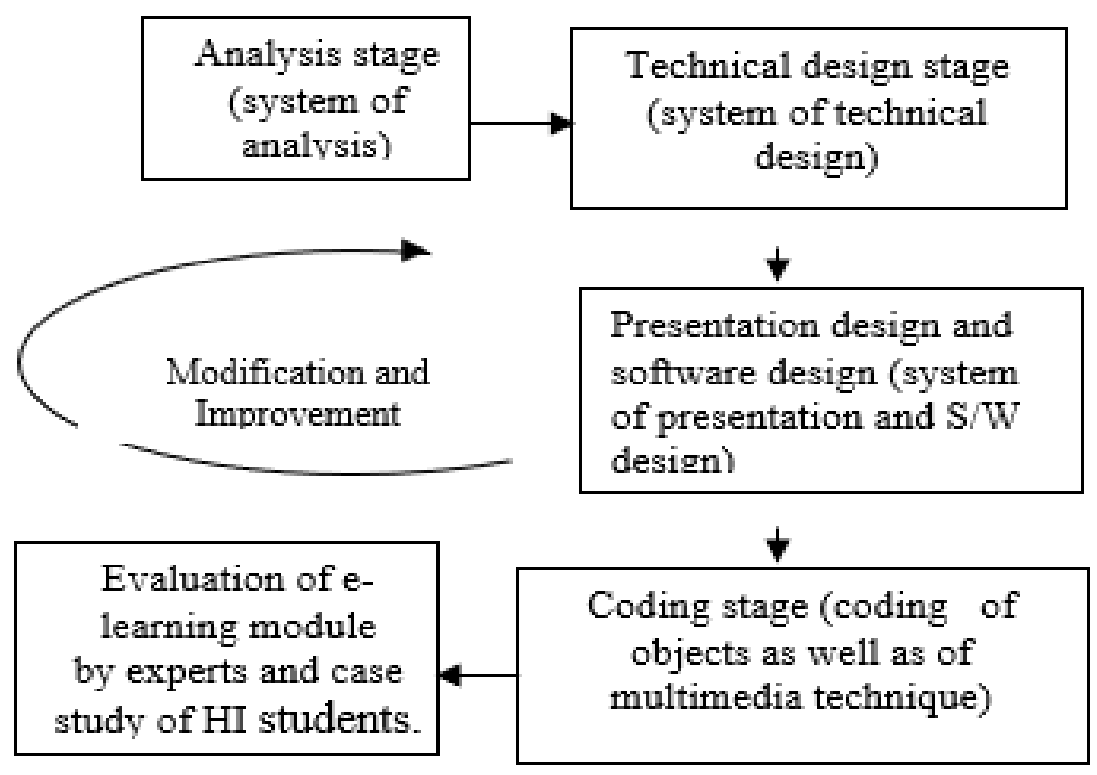

Figure 1: Stages of the Model

Now we shall display each stage individually so that the stage is represented as a system having its own elements and its mechanism during application of the model.

Before presentation of analysis system, we will display in brief the theory of teaching / learning process which forms the main frame of our desired model.

What is the difference between theory and model?

The theory means generalization of observations to predict behavior, it must be true/confidence for at least certain period of time. The model means mental picture/computational framework based on theory to simulate behavior, However the model is designed to be an ideal guide to accomplish certain task.

\section{i. Summary of Theory of Teaching / Learning Process for HI Persons Via E- Learning}

HI student receives the new information via multimedia presentation of sign language with lip movement and continuous interaction between HI student and computer presentation. Such mechanism of teaching / learning process would stimulate HI student's mind to link the new information with current / past knowledge Then HI student's mind can reconstruct the frame structure of the information. This reconstruction leads to positive change of HI student behavior. The instructional material aims at enhancing the mind frame of HI person. Therefore it should be prepared systematically so as to trigger mental activities and cause positive behavioral change. 


\section{ii. Analysis Stage}

The next diagram shows analysis stage as system and has its elements and mechanism has its elements and mechanism

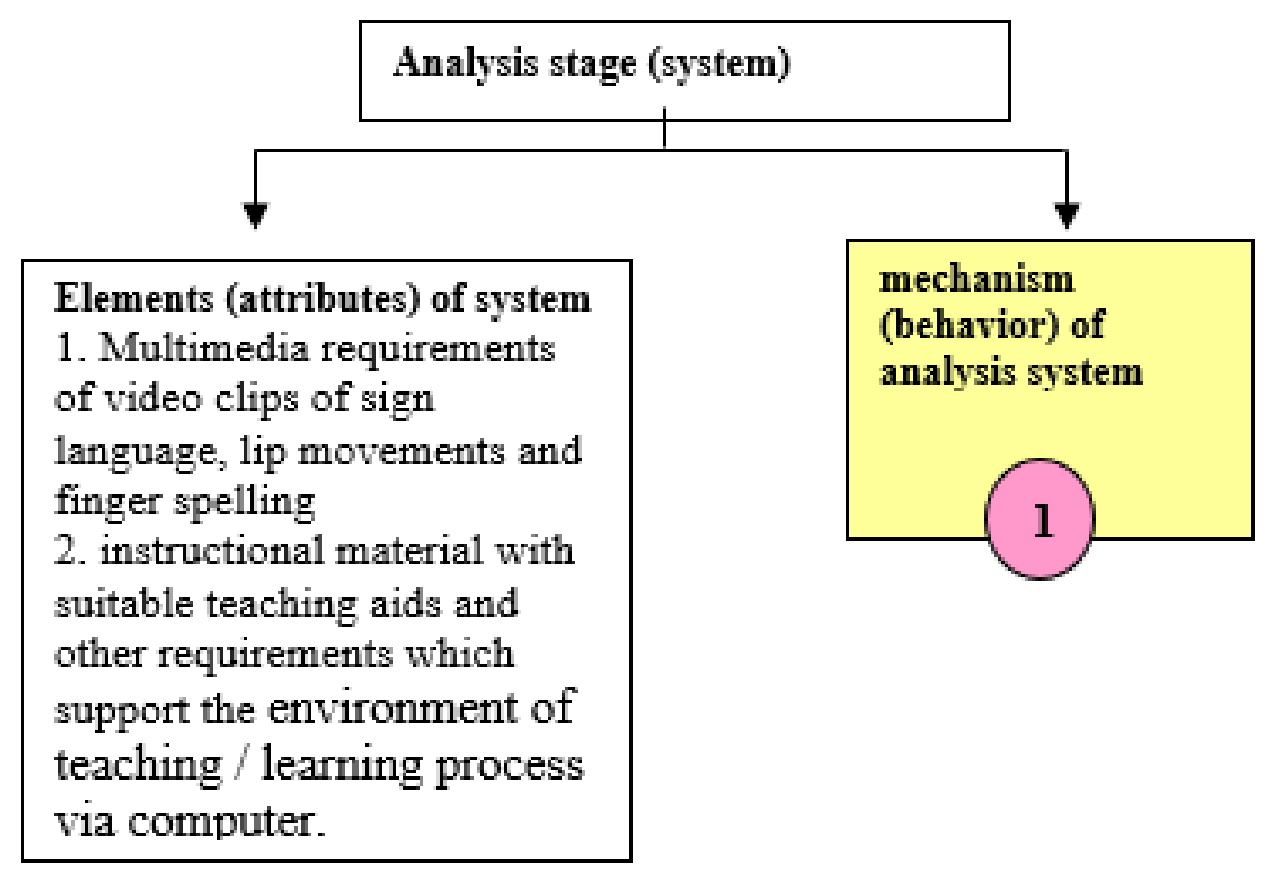

Figure 2: Analysis stage (without mechanism)

Now we shall present mechanism of analysis system.

The analysis aims at realizing the maximization of instructional outcomes (quality and quantity). As the model is built on this analysis, it is also expected to maximize the instructional outcomes. The instructional material is analyzed according to the theory of research as follows.

The main objective of the material is divided into independent sub-objectives.

Each sub-objective leads to certain activities (mental activities) to realize achievement of that subobjective.

Each activity is to be done under certain conditions. However, these conditions are created by the instructional material itself. The conditions describe the past knowledge and current experience of learner to accomplish corresponding activity. The sub-objectives represent the outcomes of eLMs. 
The following diagram shows the analysis technique in the model:
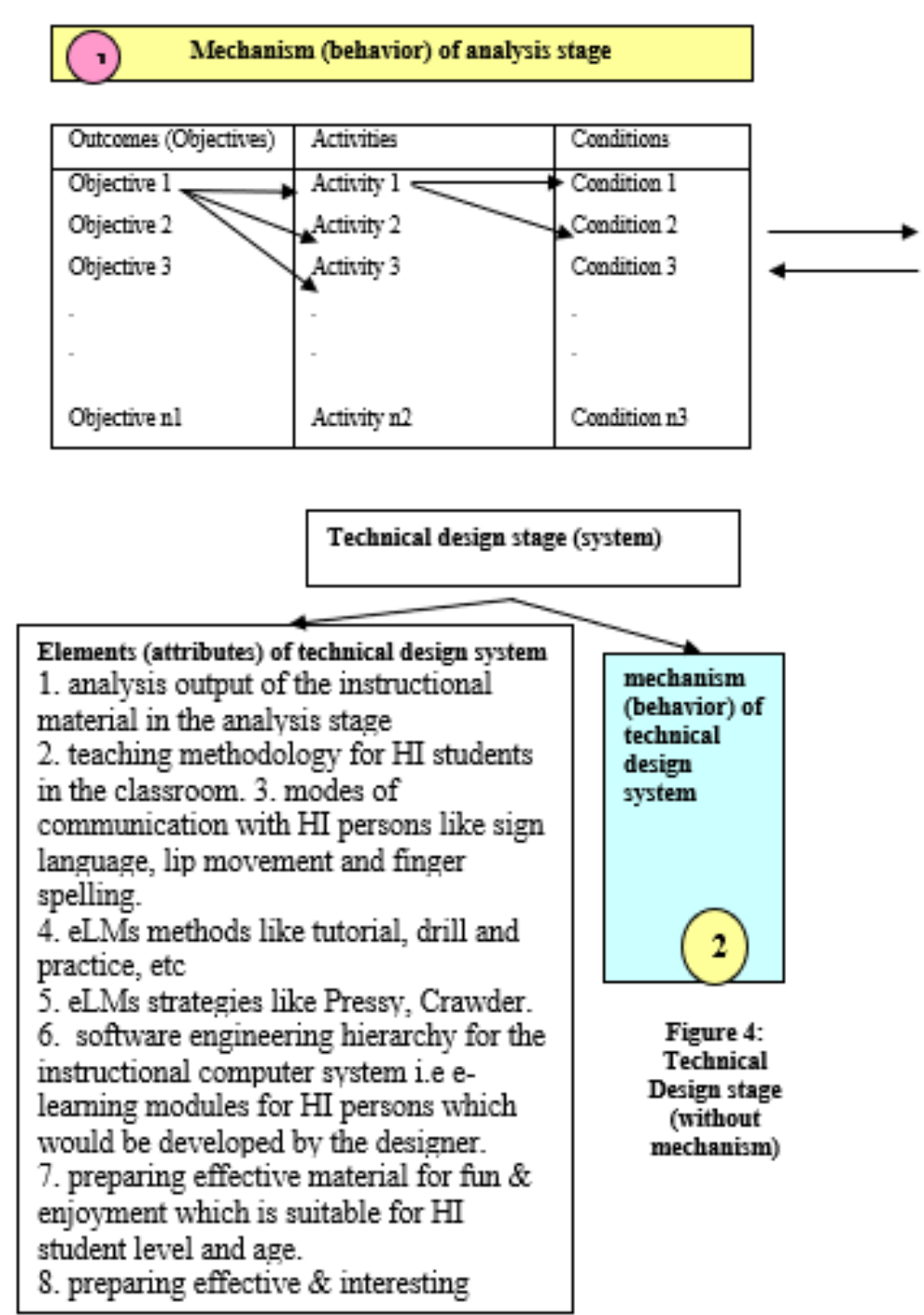

\section{Objectives:}

After dividing the main objective (of the e-learning module lesson) into subobjectives, each sub-objective is considered as independent, individual objective (objectivel, objective2,...., objective nl).

\section{Activities:}

They repregent the set of mental activities which must be held by the mind in order to achieve that objective. So they are not physical activities but set of mental sequential, interactive and integrated activities which deal with the material contents (text, exercises, pictures, etc). These are experienced by $\mathrm{HI}$ student via e-learning module.

\section{Conditions:}

There are two main types of conditions:

a- Conditions of the specific activity created by the contents of the material for those activities. conditions due to past experience and the current knowledge which have certain relation with the current activity.

b- Conditions due to the pagt. experience and current knowledge which have certain relation with the current activity.

Figure 3: Mechanism of Analysis Stage

\section{iii. Technical Design Stage}

The output of analytical stage leads to technical design, This design uses Entity-Relation (ER) type diagram. Technical design represents selecting and designing the items illustrated through the field of the following Figure 4 and Figure 5. The approach of design is called technical, because it covers development of eLMs for HI persons.

The next table describes the mechanism of technical design stage. Each element has been represented by a field of the table. Field 3 shows the whole design methodology because it includes the diagram of eLM methodology, each block in this diagram represents an element of the technical design stage. 


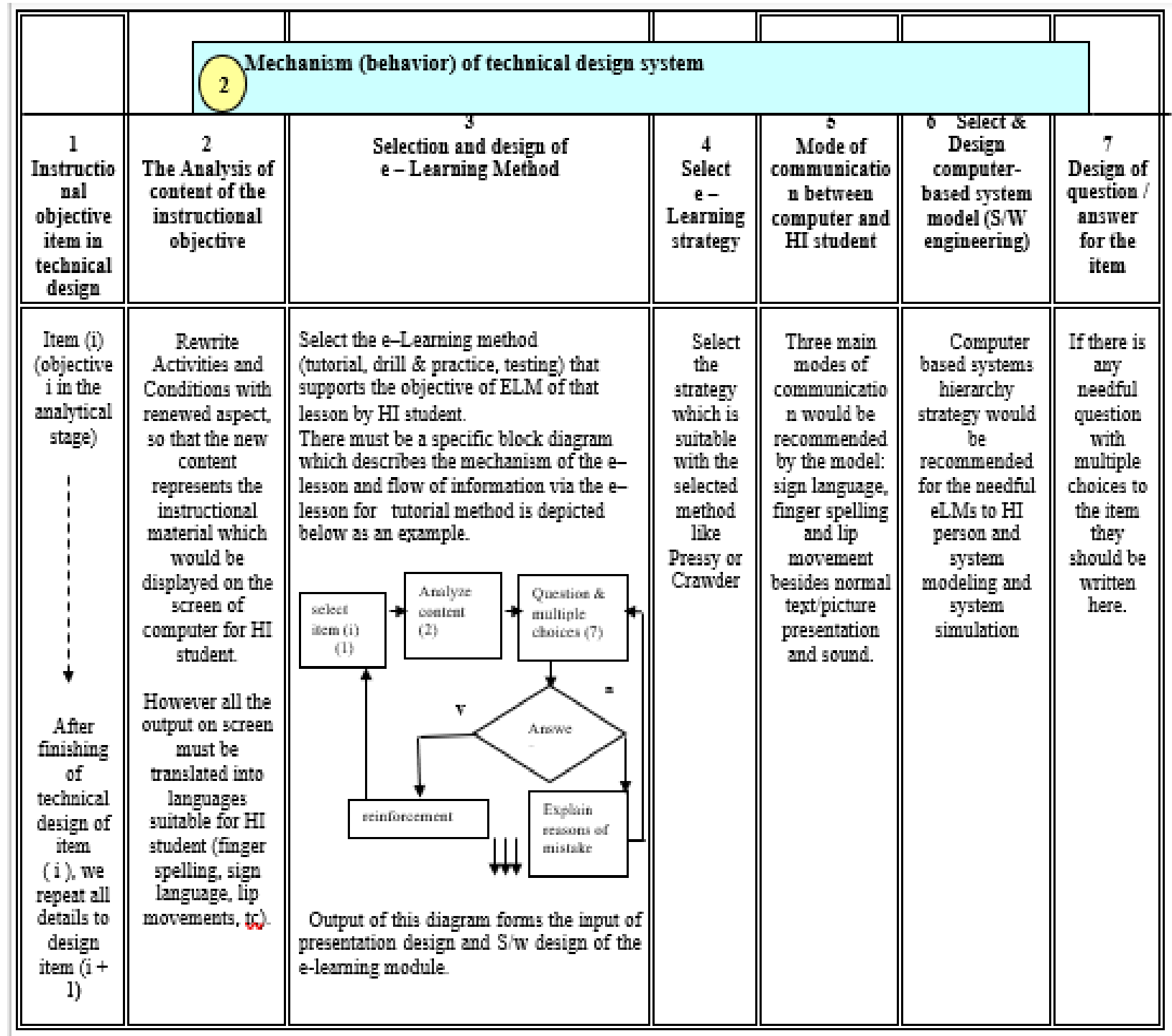

Figure 5: Mechanism of Technical Design Stage

\section{iv. Presentations and Software Design}

The output of Technical design stage leads to input of presentation and software design of Instructional Computer System for Hearing Impaired Persons.

The designer must prepare blank forms. Each paper represents an individual and separate form (screen of output) of the desired eLMs. Therefore, if the designer uses visual programming (e. $\mathrm{g}$ Visual Basic), each paper would represent an individual form of the project. Visual programming technique is strongly recommended to be used for eLMs coding. For Visual Basic there are three steps of coding of Objects design, properties of objects and coding of objects. The designer should set the object's design, their properties then coding on the paper.

Next figures (6\&7) shows a sample of terminate the technical design into Visual Basic forms. 


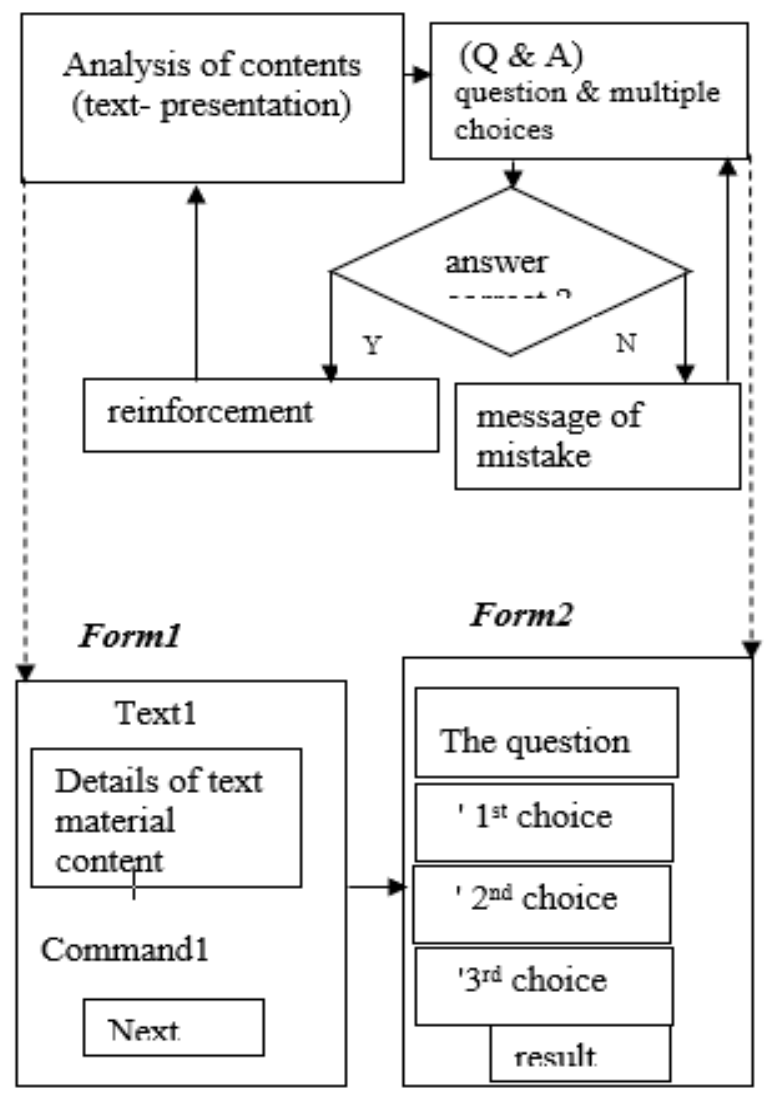

Figure 6: Block Diagram of Tutorial Item (sample)

\section{v. Q) How could the designer convert the technical design report into visual programming forms?}

The developer must study the technical design report, particularly the method of e-learning and its contents with the help of Figure 5. After studying the contents of each block in the diagram of the method, the designer would select the proper objects for the activity of that block. For example, Fig.6 represents an e-learning module of tutorial item.

\section{vi. Coding Stage}

After finishing all of presentation forms and corresponding software design, the developer would transform all the forms into visual programming coding with needful specification of coloring, dimensions, fonts, etc. The output for each word / letter must be translated into sign language or finger spelling or lip movement (according to the developer's decision). The developer can use certain functions and commands of the visual programming language for that linking / translation. Alternatively, he may use data base technique.

Each word must be linked with its corresponding clip file of sign language or each letter must be linked with its corresponding picture file of alphabets of finger spelling

\section{vii. Evaluation for Modification and Improvement}

After finishing the applied e-learning module for HI person, the developer may evaluate his elearning module by presenting trial run to teachers of HI students and Experts to get feedback from them. Then the designer would modify his e-learning module for improvement and put it in its final form to be disseminated to HI person. 


\section{Q) What are the categories of the Experts and Professionals who would try eLMs to evaluate them?}

There are four types of Experts:

Experts in the field of Instructional Computer Science, to evaluate the e-learning method, strategy, technical design, analysis of contents, etc.

Experts in HI education to evaluate the HI teaching methodology via e-learning module. The mode of communication, HI learning environment via e-learning, effectiveness of sign language clips and finger spelling pictures used, etc are also evaluated. This quality audit is an important contribution of our research.

Experts in the field of computer science and software Engineering to evaluate the effectiveness of software design, algorithms used, files design, data base used (if any), data structure technique (if any ) and multimedia technique used (clips, motion, pictures, colors, and voice " if any " ).

Teachers of the instructional material of the e-learning module, particularly who teach HI students. They evaluate the contents of the instructional material and how best the e-learning module presents these contents. The questions, reinforcement, teaching aids used via e-learning module, etc are also evaluated.

\section{Development of eLMs}

Different types of e-lessons (tutorial, drill and practice, testing, etc). Also different topics (mathematics, language, general science, etc.). Also different categories of HI student and modes of communication. How can the designer judge and decide the right eLM for his desired lesson?

We will answer in general aspect because it is hard to cover all probabilities of eLMs for HI students. The following items give basic idea for answer the question.

a) First designer must decide purpose of lesson, then according to purpose he could select type, mechanism and strategy of eLM

\section{Tutorial (text presentation)}

Purpose: to present new instructional material or to promote current instructional skills of the candidate.

Steps: Introduction $\rightarrow$ tutorial section $\rightarrow$ present information $\rightarrow$ question and answer session ( Q $\&$ A ) $\rightarrow$ feedback.

Drill \& Practice (exercises)

Purpose: practicing and enhancement of skills of the learner's mind, particularly to grasp the information by solving different exercises (e. g. Mathematics)

\begin{tabular}{|c|c|}
\hline $\begin{array}{l}\text { Output of tutorial } \\
\text { lesson / normal } \\
\text { lesson in classroom }\end{array}$ & $\begin{array}{l}\text { Input of drill and } \\
\text { practice lesson }\end{array}$ \\
\hline
\end{tabular}

Steps: Introduction $\rightarrow(\mathrm{D} \& \mathrm{P})$ session $\rightarrow$ select item $\rightarrow(\mathrm{Q} \& \mathrm{~A}) \rightarrow$ Score/evaluation $\rightarrow$ Closing $\rightarrow$ Feedback. 


\section{Problem Solving}

Purpose: To test students skills of problem-solving logic and ability to follow direction (algorithm). Primarily used to augment higher order of thinking skills so it may activate the brain storming of learner. This method is suitable for physical sciences and technology.

An Algorithm is defined as step by step logical and mathematical procedure, expressed in common natural language , to solve a class of problems

problem $\rightarrow$ display assumption for describing / solving that problem $\rightarrow$ check the chosen assumption $\rightarrow$ feedback

\section{Testing (e-exam)}

Quiz designed to test the knowledge or achievement of subjects by learners to let them know which questions were missed and what the correct answers to them were (score can be seen immediately

\begin{tabular}{|l}
$\begin{array}{l}\text { Out put of all other } \\
\text { modules besides } \\
\text { classroom lessons }\end{array}$ \\
\hline
\end{tabular}

Steps: Display question $\rightarrow$ answer by learner $\rightarrow$ score $\rightarrow$ feedback.

\section{Games (inmstructional computer games)}

Purpose: To provide an environment that facilitates learning or update skills. Games however or may not mimic reality. Games offers fun of use, learning under light environment.

Steps: Introduction $\rightarrow$ game section $\rightarrow$ presentation $\rightarrow$ scenario $\rightarrow$ action required $\rightarrow$ closing $\rightarrow$ score $\rightarrow$ system updates $\rightarrow$ student action.

There is no certain diagram to describe game method because each game has its own steps and Scenario.

b) Also type of topic, level and age of HI students: for exercise use drill and practice like IImatheatics. for primary school and low level use instructional computer games, etc.

c) Mode of communication: standard level are comfortable with sign language, sign language is universal and easy to be learned, Lip movement is very effective but needs advanced skills, therefore such mode needs more practice to understand. Finger spelling is somewhat difficult but HI students who are Deaf and Dumb form birth are needed to be communicated with finger spelling. d) Using of Visual Programming is strongly recommended because it offers to the designer the chance to design the lesson so that each form provide ideal environment simulation to classroom. Also, HI student can learn their lessons in sequence gradually form by form.

e) Some important decisions should be adopted by the developer when he/she considers strategies for teaching HI student like use simple, clear, common and words, present sentences slowly with ability of repeating items, etc. (kindly look for Ref. $7 \& 8$ )

\section{Conclusion}

1) This model based on theory of teaching / learning process for HI persons via e-learning, therefore eLMs developed by using this model would acquire the advantages and benefits of this theory as shown:

- eLMs would realize maximization of the instructional outcomes. 
- eLMs would realize effective instructional outcomes by linking and interacting the new information with the past knowledge / current experience of the related topic. As a result of such interaction and linking mind of HI student would reconstruct the knowledge frame of information positively, so the desired change in HI student's behavior would changed as desired.

- Continues reinforcement and feedback and fun and enjoinment form a major activities of eLMs process, so that such eLMs would be a friendly learning tool for HI student.

2) The systematic and integrated approach of developing this model offers to the designer the ability to design any eLM for any given topic for any category of HI student.

3) eLMs developed by this model give the chance to HI student to take the main / active role in teaching / learning process, such central role realizes effective advantages for HI student according to literature of instructional technology and modern approach of teaching.

4) The model is presented as sequential stages (systems with attributes and behavior), however this approach allows the designer to code his eLMs (with the effective multimedia control components), using an object oriented technique, it is highly recommended to use Visual Programming Software like VB. Also, the designer can use OOP technique particularly for sizable instructional computer systems for $\mathrm{HI}$ persons.

\section{References}

[1] Cotton, Kathleen: Computer - Assisted - Instruction, School Improvement Research Series, Regional Education Laboratories, May 1991

[2] Hussein, Karim. Q: Computer Aided Learning of Theory of Structures (experimental study), M.Sc thesis , University of Technology, Baghdad-Iraq, 1986

[3] Hussein, Karim Q: The Role of Perceptions Theory in Developing Training Computer Models (Technical approach), Arabic Conference of Technical Education, Higher Vocational Center for Computer technology, Tripoli, Libya 26-28th FEB2000.

[4] Hussein, Karim Q. \& Al-Byati, Maha. A: Development of Instructional Computer Model using Ausubel Theory (Advanced Organizers), 1st conf of Hussein Bin Talal University, May 2004

[5] Hussein, Karim Q \& Warnerkar, C.S: e-Learning Support to Hearing Impaired Persons, ISTE, Punjab 2-3March2007

[6] Kaplan, Harriet \& Mahshie, James \& Moseley, Mary \& Singer, Beth \& Winston, Elzabeth: Design of Effective Media Materials and Technology for Deaf and Hard - of - Hearing Students. This document was prepared by National Center to Improve the Tools of Education, U.S. efface of Special Education Programs. http://idea.uoregon.edu/ ncite/documents/techrep/tech01.html

[7] Keller, Ed: Strategies for Teaching Students with Hearing Impairment, February 2004. http://www.as.wuv.edu/ scidis/hearing.html

[8] Knowles, Lan: Teaching Deaf and Hearing-Impaired Students: The University of Sheffield, Uk. http://www.Shef.ac.UK/disability/teachin hearing/5-strategies.html

[9] Landa, L: Algorithmization in Learning and Instruction, Englewood cliffs, NJ, Educational Technology publications, 1974 http:// www.wim.edu/users/mfill/Landa .htm

[10] Mergel, Brenda: Instructional Deign \& Learning theory, Educational Communications and Technology, University of Sasktchwan, May 1998. www.usask.ca

[11] Poobrasert, Onintra \& Mguine, Brain: Knowledge Engineering in Multimedia Design and Computer Assisted Learning for Special Needs Training: Effectiveness, The 9th World MultiConference on Systemic, Cybernetics and Informatics July 10-13, 2005 - Orlando, Florida, USA http://www.iiisci.org/sci2005/proceedingssci/vol8-2001.asp

[12] Snyder, D. P. (2004, January). A look at the Future: Is Technology the Answer to Education's LongTerm Staffing Problems? American School Journal. Retrieved June 17, 2007, from 
http://www.asbj.com/2004/01/0104technologyfocus.html

[13] Straetz, Katja \& Kaibel, Andreas \& Raithe, Vivian: An e-Learning Environment for Deaf Adults. http://www.ecotec.com/mes/projects/evident.html

[14] Waston, Léonie: Multimedia: Enhancing Ability $\mathrm{ttp}: / / \mathrm{www}$. skillsforaccess.org.uk/articles,phd?id=152\#auther\#auther

[15] Important Links for e - Learning and Computer Assisted Instruction http://www.ceap.wcu.edu/houghton/learner/Look/CAI.html www.prel.org : http://www.wikipedia.org http://wikiindex.com/Wiki_Index : $\quad$ http://www.world66.com/ http://c2.com/cgi/wiki : $\quad$ http://wikitravel.org/en/

*Corresponding author.

E-mail address: karimzzm@ yahoo.com/ qabas_a@ uomustansiriah.edu.iq 